\title{
Whole-Exome Sequencing for Identifying Genetic Causes of Intellectual Developmental Disorders
}

This article was published in the following Dove Press journal:

International Journal of General Medicine

\author{
Yu-Xiong Guo ${ }^{1,2, *}$ \\ Hong-Xia Ma ${ }^{1-3, *}$ \\ Yu-Xin Zhang ${ }^{2}$ \\ Zhi-Hong Chen ${ }^{2}$ \\ Qiong-Xiang Zhai ${ }^{1,2}$
}

'The Second School of Clinical Medicine, Southern Medical University, Guangzhou, 510280, People's Republic of China; ${ }^{2}$ Department of Pediatrics, Guangdong Provincial People's Hospital, Guangdong Academy of Medical Sciences, Guangzhou, 510080, People's Republic of China; ${ }^{3}$ Department of Pediatrics, Affiliated Hospital of Guangdong Medical University, Zhanjiang, 524000, People's Republic of China

*These authors contributed equally to this work
Correspondence: Qiong-Xiang Zhai Department of Pediatrics, Guangdong Provincial People's Hospital, Guangdong Academy of Medical Sciences, 106

Zhongshan Second Road, Yuexiu District, Guangzhou, 510080, People's Republic of China

Tel $+86-2083827812-76222$

Fax +86-20-8328480

Email zhaiqx_24I@I63.com
Background: Intellectual developmental disorders (IDD) generally refers to the persistent impairment of cognitive activities and mental retardation caused by physical damage to the brain or incomplete brain development. We aimed to explore its genetic causes.

Methods: In this study, 21 IDD patients were recruited. The Gesell developmental scales (GDS) and Wechsler intelligence scale for children (WISC) were used to assess the impaired level of intellectual development for all probands. A superconducting MRI scanner (Philips AcsNT 3.0 T Philips, Best, The Netherlands) was used to perform a plain MRI scan of the skull on the probands. The whole-exome sequencing was carried out using next-generation sequencing in all probands and their families.

Results: Eight had seizures and four had typical characteristics of autism. Pregnancy and delivery were uneventful except for three patients. Moderate IDD (52.4\%) accounted for the majority. The abnormal MRI results included ventriculomegaly, pachygyria, broadening external cerebral space, abnormal signal change and agenesis of corpus callosum. Eleven variants were identified, including the variant in CREBBP, MECP2, HCFC1, ATRX, $R A B 39 B, C L C N 4, D Y R K 1 A$ and $C A S K$ genes. The function areas result of gene-positive group were compared to that of gene-negative group. Not significant $(\mathrm{p}>0.05)$ items were revealed after this analysis.

Conclusion: Eleven variants were identified, including the variant in CREBBP, MECP2, $H C F C 1, A T R X, R A B 39 B, C L C N 4, D Y R K 1 A$ and $C A S K$ genes. The function areas result of gene-positive group were not significantly different from the gene-negative group.

Keywords: intellectual developmental disorders, gene variant, whole-exome sequencing

\section{Introduction}

Intellectual developmental disorders (IDD) generally refers to the persistent impairment of cognitive activities and mental retardation caused by physical damage to the brain or incomplete brain development. ${ }^{1}$ As a result of genetic variation, infection, poisoning, head injury, craniocerebral malformation or endocrine abnormalities and other harmful factors, the brain of the fetus or infant cannot develop normally or completely, so that the development of intellectual activities stays at a relatively low stage. ${ }^{2}$

The intelligence of children with IDD is significantly lower than the average intelligence level of normal people. ${ }^{3}$ The average intelligence quotient (IQ) of a normal person is 100 . A child with an IQ of 100 is considered normal, and a child with an IQ below 70 is said to be "significantly below" the average (simplified to "below 70"). ${ }^{4}$ Only two out of 100 children of the same age had IQ below 70." The onset of mental retardation is usually in the stage of development, specifically before 
the age of $18 .^{6}$ This distinguishes mental retardation that occurs during development from mental retardation that occurs later in life for a variety of reasons. ${ }^{7}$ The incidence of mental retardation generally does not exceed $2 \%$. Some children with mental retardation are accompanied by abnormal behaviors and mental diseases to a certain extent, which will also affect their daily social life. ${ }^{8}$ According to the new development trend, people pay more and more attention to the social adjustment disorder of children with intellectual disabilities, because the social adjustment disorder has a direct impact on their personal function and how to participate in social life. ${ }^{9}$ Children with IDD have obvious obstacles in adapting to daily social life. Young children with mental retardation in daily life for action, language development, not interpersonal communication, kindergarten or primary school is more difficult. In this study, 21 IDD patients were recruited to explore its genetic causes.

\section{Materials and Methods}

\section{Ethical Compliance}

This study was conducted in accordance with the Declaration of Helsinki and approved by the Ethics Committee of Guangdong Provincial People's Hospital. The parents of the patient in Figure 1 provided informed consent for the images to be published.

\section{Subjects}

In this study, 21 patients with intellectual developmental disorders (IDD) from the Department of Pediatrics, Guangdong Provincial People's Hospital were recruited. The inclusion criteria were: 1) age at first exam was from 3months to 18years; 2) IDD:ID: IQ<70, assessed by WISC; DD: $\mathrm{DQ}<76$ in two or more developmental domains assessed by Gesell Developmental Scale. And patients with the history of intoxication, cranial trauma or central nervous system infection were excluded. Intellectual developmental disorder was defined as impaired intellectual functioning and adaptive behaviour with an onset before 18 years old. The study was approved by the Ethics Committee of Guangdong Provincial People's Hospital. Informed consent was obtained from the parents. The Gesell developmental scales (GDS) and Wechsler intelligence scale for children (WISC) were used to assess the impaired level of intellectual development for all probands. A superconducting MRI scanner (Philips AcsNT 3.0 T Philips, Best, The Netherlands) was used to perform a plain MRI scan of the skull on the probands.

\section{Molecular Analysis}

The whole-exome sequencing was carried out using nextgeneration sequencing (NGS) in all probands and their families. Genomic DNA was obtained from peripheral blood cells by standard procedures. DNA samples were extracted from blood samples using the Genomic DNA Extraction Kit (TIANGEN, Beijing, China), according to the manufacturer's protocol. The NGS procedure included ultrasonic fragmentation of DNA fragments, library construction, hybridisation capture, capture library amplification and purification and other standard procedures. Exomes were enriched with a use of the SureSelect Target Enrichment System Kit (Agilent, USA). The hybridisation capture for genomic DNA library was prepared using the Sureselect XT Reagent Kit. Targeted NGS including exon capture and sequencing on Genome Analyzer II platform (Illumina, Inc., San Diego, CA, USA) was performed for each index patient. Subsequently, the HGMD database (http://www. hgmd.cf.ac.uk/ac/index.php), dbSNP database (https:// www.ncbi.nlm.nih.gov/snp/), gnomAD database (https://gno mad.broadinstitute.org/), and 1000 Genome database (https://www.internationalgenome.org/) were used for annotating the detected variations. Variant pathogenicity was
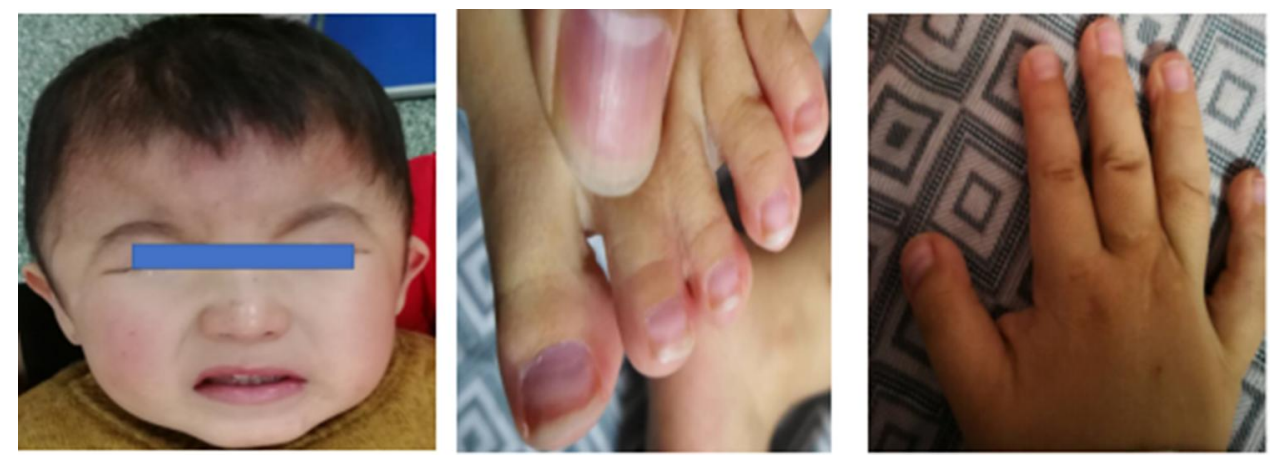

Figure I Facial and limb features of the patient. 
analyzed in silico tool Mutation taster, Sorts Intolerant From Tolerant (SIFT), Polyphen2, Provean, M-CAP, REVEL. The pathogenicity of gene variation was analyzed according to American College of Medical Genetics and Genomics (ACMG) guidelines.

\section{Statistical Methods}

The descriptive statistics were used to present the clinical characteristics of the patients. The GDS assessment results were presented as developmental quotient (DQ). The intelligence quotient (IQ) of 4 children with IDD was assessed with Wechsler scale. In the intelligence development assessment (Gesell results), the results of gene-positive group were compared to that of genenegative group. Using a two-tailed paired $T$-test. An alpha level of 0.05 (two-tailed) was our threshold of statistical significance.

\section{Results}

\section{The Clinical Features of 2I Patients with Intellectual Developmental Disorders}

As shown in Table 1, the male patients (85.7\%) accounted for a large proportion of the probands. Eight of them with seizures were identified and four of them had typical characteristics of autism, including the three female patients. Table 1 shows the clinical features of each patient. Pregnancy and delivery were uneventful except for three patients (proband $\# 2,11,12$ ). The degree of IDD ranges from mild to profound. And moderate IDD (52.4\%) accounted for the majority. Brain MRI showed normal except for eight patients. The abnormal MRI results included ventriculomegaly, pachygyria, broadening external cerebral space, abnormal signal change and agenesis of corpus callosum.

\section{The Gene Variants in I I Children with Intellectual Developmental Disorders}

Among the 21 patients, 11 variants were identified, including the variant in $C R E B B P$ (Figures 1 and 2), MECP2, HCFC1, ATRX, RAB39B, CLCN4, DYRK1A and $C A S K$ genes (Table 2). The $M E C P 2$ gene variants and $H C F C 1$ variants were found two or more times. Six de novo variants $(28.6 \%)$ and 5 hemizygous variants $(23.8 \%)$ were identified. Most variants were missense variants.

\section{Comparison of Gesell Results Between Gene Positive and Negative Group}

As shown in Tables 3 and 4, of the 21 patients, the intelligence quotient of 4 patients with IDD was assessed with Wechsler scale and 17 patients was assessed with Gesell scale. A preliminary global analysis of the Gesell results was performed. Analysis of Gesell developmental scales showed that function areas, including adaptation, gross motor, fine motor, individual communication, and language development. The function areas results of genepositive group were compared to that of gene-negative group. Not significant $(\mathrm{p}>0.05)$ items were revealed after this analysis.

\section{Discussion}

At least one in every 100 children worldwide is affected by an intellectual disability, which not only severely limits their ability to learn, but also affects their daily lives. Mental retardation is often associated with autism-related symptoms, and studies have found that many genes are present in both disorders. The study of its pathogenesis gene provides a new idea for the diagnosis and clinical treatment of the disease, and enriches the relevant knowledge of brain development and functional expression, and ultimately provides help for individualized treatment.

In our study, 11 variants were identified, including the variant inCREBBP, MECP2, HCFC1, ATRX, RAB39B, CLCN4, DYRK1A and CASK genes. Compared with the gene-negative patients, the gene-positive patients were found to have developmental delay at an earlier age, mostly within 1 year old. Moreover, a higher incidence of complications was found in gene-positive patients, including epilepsy, ASD. One patient had severe structural abnormalities, pachygyria. And convulsions occur prior to developmental delay in some patients. There was no significant difference in intellectual development between the two groups. The genetic pattern of these 11 patients was X-linked inheritance and De Novo variation.CREBBP gene is widely expressed and is involved in the transcriptional co-activation of many different transcription factors, and plays a key role in embryonic development, growth control, and homeostasis by binding chromatin remodeling to transcription factor recognition. Variants in this gene cause Rubinstein-Taybi syndrome (RSTS). ${ }^{10-12}$ Chromosomal translocations involving this gene are associated with acute myeloid leukemia. Selective splicing results in multiple transcriptional variants encoding different subtypes. In this study, we have reported and 
Table I The Clinical Features of 2I Patients with Intellectual Developmental Disorders

\begin{tabular}{|c|c|c|c|c|c|c|}
\hline Proband & $\begin{array}{l}\text { Mutant } \\
\text { Genes }\end{array}$ & $\begin{array}{l}\text { Visiting } \\
\text { Age }\end{array}$ & $\begin{array}{c}\text { Clinical } \\
\text { Phenotype }\end{array}$ & $\begin{array}{c}\text { Intellectual } \\
\text { Developmental } \\
\text { Disorder }\end{array}$ & History of Birth & MRI \\
\hline $\mathrm{I}, \mathrm{M}$ & RAB39B & $11 \mathrm{~m}$ & IDD & Mild & Normal & Normal \\
\hline $2, M$ & ATRX & $22 \mathrm{~m}$ & IDD, EP & Mild & Premature & Normal \\
\hline $3, M$ & CLCN4 & $36 \mathrm{~m}$ & IDD, EP & Mild & Normal & Ventriculomegaly \\
\hline $4, M$ & $\mathrm{HCFCl}$ & $41 \mathrm{~m}$ & IDD & Moderate & Normal & Pachygyria \\
\hline $5, M$ & $\mathrm{HCFCl}$ & $34 \mathrm{~m}$ & IDD, EP & Moderate & Normal & Normal \\
\hline $6, M$ & DYRKIA & $8 \mathrm{~m}$ & IDD, EP & Mild & Normal & Ventriculomegaly \\
\hline $7, \mathrm{~F}$ & CASK & $56 \mathrm{~m}$ & $\begin{array}{l}\text { IDD, Rett } \\
\text { syndrome }\end{array}$ & Severe & Normal & Normal \\
\hline $8, \mathrm{~F}$ & MECP2 & $68 \mathrm{~m}$ & IDD, ASD & Moderate & Normal & Normal \\
\hline $9, \mathrm{~F}$ & MECP2 & $67 m$ & IDD, ASD, EP & Moderate & Normal & Normal \\
\hline $10, M$ & MECP2 & $6 y 9 m$ & IDD, EP & Moderate & Normal & Normal \\
\hline $\mathrm{II}, \mathrm{M}$ & CREBBP & $29 m$ & IDD & Severe & $\begin{array}{c}\text { Premature, } \\
\text { Intrauterine distress }\end{array}$ & $\begin{array}{l}\text { Dilated bilateral lateral ventricle } \\
\text { and third ventricle }\end{array}$ \\
\hline $12, M$ & None & $20 \mathrm{~m}$ & IDD & Severe & Intrauterine distress & Dilated external cerebral space \\
\hline $13, M$ & None & $70 \mathrm{~m}$ & IDD & Profound & Normal & $\begin{array}{l}\text { Abnormal signals from the left } \\
\text { lateral ventricle }\end{array}$ \\
\hline $14, M$ & None & $70 m$ & IDD & Severe & Normal & Agenesis of corpus callosum \\
\hline $15, M$ & None & $8 m$ & IDD, EP & Mild & Normal & Normal \\
\hline $16, M$ & None & $21 \mathrm{~m}$ & IDD & Moderate & Normal & Normal \\
\hline I7, M & None & $\mathrm{IIm}$ & IDD & Moderate & Normal & Normal \\
\hline $18, M$ & None & $8 m$ & IDD, EP & Moderate & Normal & Normal \\
\hline $19, M$ & None & $13 y$ & IDD & Moderate & Normal & Normal \\
\hline $20, M$ & None & $13 y$ & IDD, ASD & Moderate & Normal & $\begin{array}{l}\text { Abnormal signal in the right frontal } \\
\text { area }\end{array}$ \\
\hline $2 I, M$ & None & $2 y 2 m$ & IDD & Moderate & Normal & Normal \\
\hline
\end{tabular}

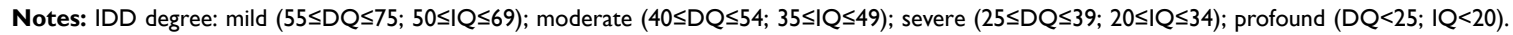

Abbreviations: IDD, intellectual developmental disorder; EP, epilepsy; ASD, autism spectrum disorders; $y$, years; m, months; M, male; F, female.

analyzed a case of de novo frameshift variant in the CREBBP gene associated with RSTS. The variant has not been reported in the literature to date. The congenital lacrimal puncta deficiency of the right eye and the subsequent acute dacryocystitis, special facial features, broad thumbs and broad halluces, developmental delay and congenital heart disease in the patient were consistent with RSTS. The study enlarges existing knowledge of the molecular spectrum of the pathogenic CREBBP gene and assists the diagnosis and treatment of RSTS. The treatment of this disease is currently supported by epigenetics. It is important to follow up the growth and development. ${ }^{12}$

The defect in the MECP2 gene ${ }^{13}$ on the $\mathrm{X}$ chromosome (Xq28) can cause Rett syndrome, which is a complex behavioral and motor neurologic disease. Rett syndrome is a neurological disorder that often affects girls, characterized by autism-like behavior, loss of motor control, irregular breathing and bone problems. Girls with Rett syndrome 

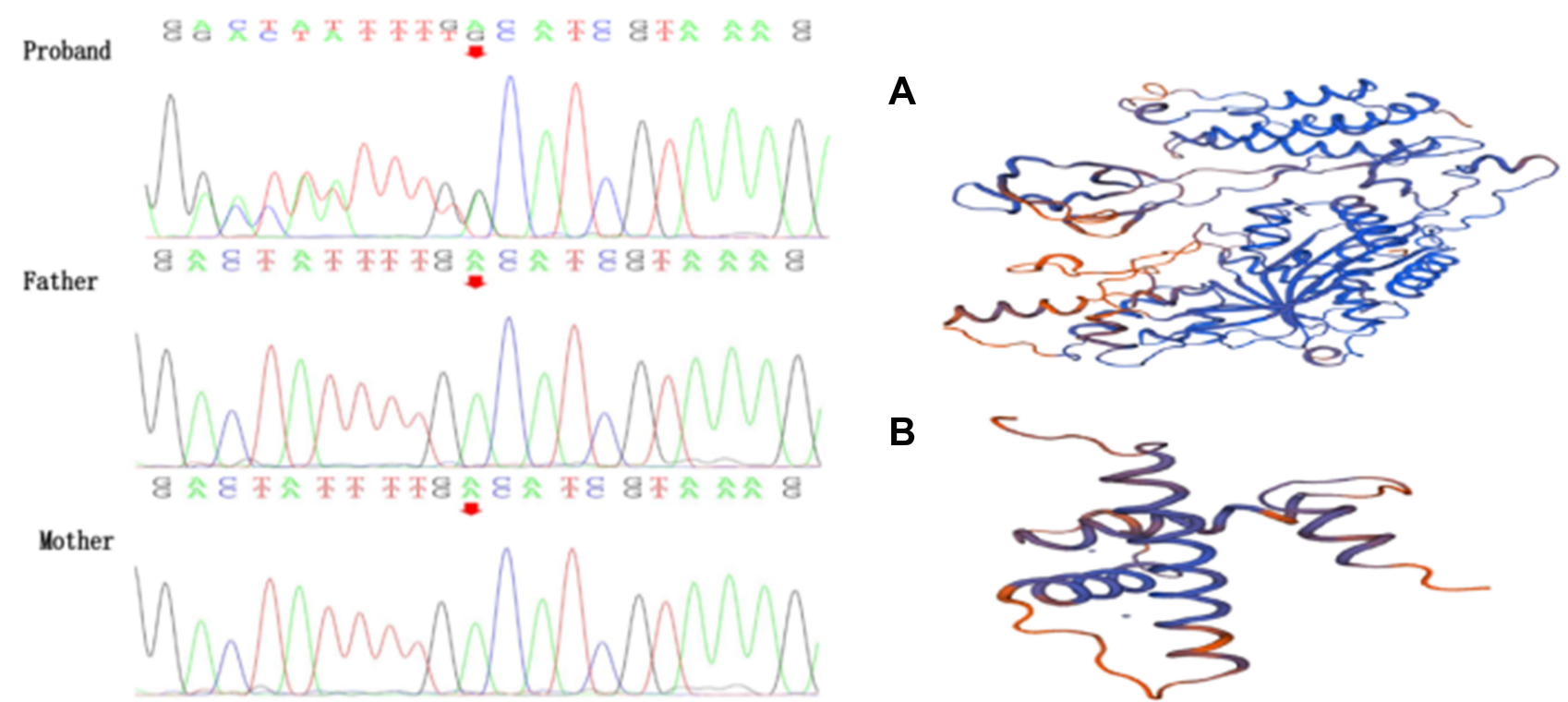

Mother

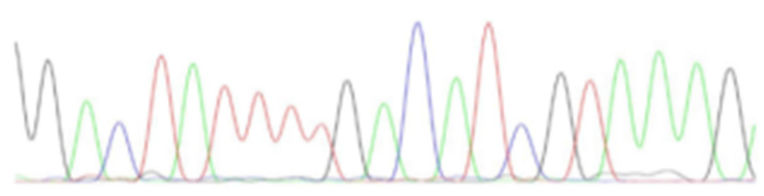

Figure 2 (Left): Chromatogram from Sanger sequencing of the CREBBP variant in the family. (Right): The protein tertiary structure of normal CREBBP protein (A) and mutant CREBBP protein (B) according the SWISS-MODEL analysis.

usually do not show symptoms until 18 months later. Rett syndrome is a sex chromosomal dominant neurological disorder that occurs in approximately 1 in 10,000 to 1 in 23,000 girls. In this study, two female patients with $M E C P 2$ variant presented ASD phenotype, but the other patient with $C A S K$ variant was diagnosed Rett syndrome. $C A S K^{14}$ is a key skeleton protein and the first protein to play a role in synaptic development. Studies have shown that CASK gene variant can lead to abnormal flow of calcium ions in neurons, affecting the development and plasticity of the nervous system, and is an important cause of $\mathrm{x}$-linked mental retardation in humans. $H C F C 1$ defect ${ }^{15}$ can cause a disorder in which intellectual function is significantly below average, associated with adaptive behavior disorders, and in which mental retardation during development is the only major symptom of non-syndromic $\mathrm{X}$-associated mental retardation, whereas syndromic mental retardation is associated with physical, neurological, and/or psychiatric symptoms. In addition to developmental delays, imaging examination in proband \#4 with $H C F C l$ variant showed pachygyria and proband $\# 5$ developed epilepsy. These characteristics are consistent with the syndromic $\mathrm{X}$-associated mental retardation. ATR $X^{16}$ regulates the binding of nuclear matrix and chromatin and indicates that it is involved in the interphase gene regulation and chromosome separation in mitosis. The gene variant is usually associated with $\mathrm{X}$ linked alpha thalassemia/mental retardation (ATR-X) syndrome. These variants lead to different changes in DNA methylation patterns, which may provide a link between chromatin remodeling, DNA methylation, and gene expression during development. $R A B 39 B^{17}$ encodes the Rab family. Rab proteins are small GTPases involved in vesicle transport. Variants in the gene are associated with $\mathrm{x}$-chromosome-related cognitive impairment. We found a $R A B 39 B$ variant $\mathrm{L} 88 \mathrm{del}$ in proband $\# 1$. The patient presented mild IDD. The CLCN4 gene ${ }^{18}$ is associated with X-linked early infantile epileptic encephalopathy (EIEE). Additionally, the CLCN4 gene has preliminary evidence supporting a correlation with X-linked intellectual disability. The proband \#3 with CLCN4 variant suffered convulsions at 5 months of age. He had a febrile seizure followed by afebrile convulsions and developmental delay. The clinical phenotype was consistent with EIEE. DYRK1A kinase ${ }^{19}$ is involved not only in neurodevelopmental processes, but also in maintaining normal brain function in adults. We found a De novo nonsense mutation in DYRK1A. The proband presented mild IDD and epilepsy. According to ACMG, the variant was evaluated to be pathogenic.

\section{Conclusion}

Eleven variants were identified, including the variant in CREBBP, MECP2, HCFC1, ATRX, RAB39B, CLCN4, $D Y R K 1 A$ and $C A S K$ genes. The function areas result of gene-positive group were not significantly different from the gene-negative group. 


\begin{tabular}{|c|c|c|c|c|c|c|c|c|c|c|c|}
\hline 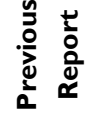 & $\stackrel{\circ}{z}$ & $\stackrel{\circ}{z}$ & $\stackrel{\tilde{\nu}}{\sim}$ & ㅇ & ż & $\stackrel{\tilde{\nu}}{\nu}$ & ㅇ & $\stackrel{\tilde{\nu}}{\tau}$ & 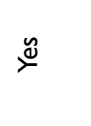 & ¿o & ㅇ \\
\hline$\sum_{U}^{U}$ & 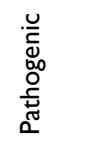 & 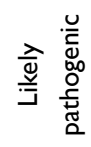 & 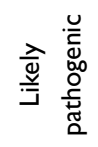 & 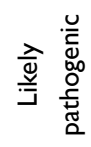 & 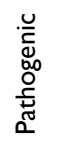 & 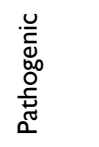 & 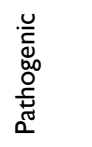 & 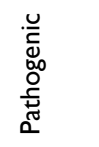 & 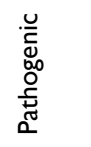 & 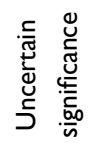 & 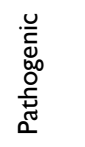 \\
\hline 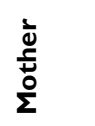 & 1 & + & $z$ & + & + & 1 & 1 & 1 & 1 & 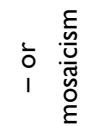 & 1 \\
\hline \multirow{2}{*}{ 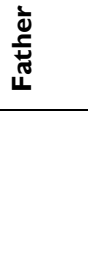 } & 1 & 1 & $z$ & 1 & 1 & 1 & 1 & 1 & 1 & 1 & 1 \\
\hline & $\begin{array}{l}\stackrel{O}{O} \\
\stackrel{0}{E} \\
\stackrel{D}{0}\end{array}$ & 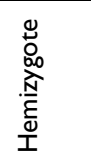 & 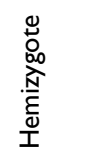 & 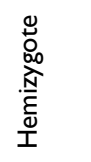 & 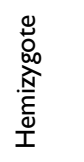 & 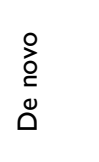 & $\begin{array}{l}\stackrel{0}{0} \\
\stackrel{0}{0} \\
\stackrel{0}{0}\end{array}$ & $\begin{array}{l}O \\
o \\
\stackrel{0}{0} \\
D \\
\Delta\end{array}$ & $\begin{array}{l}0 \\
\text { o } \\
\stackrel{5}{0} \\
\stackrel{0}{0}\end{array}$ & 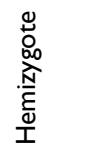 & 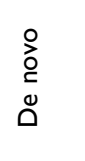 \\
\hline 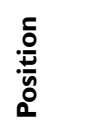 & 1 & $\begin{array}{l}\frac{\infty}{\bar{\sigma}} \\
\frac{\dot{x}}{凶}\end{array}$ & $\begin{array}{c}\infty \\
\stackrel{\infty}{\bar{x}} \\
\dot{w}\end{array}$ & $\begin{array}{l}\frac{\infty}{\tau} \\
\frac{\bar{d}}{凶}\end{array}$ & $\begin{array}{l}\overline{\bar{c}} \\
\overline{\bar{x}} \\
\overline{4}\end{array}$ & 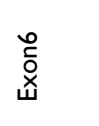 & $\frac{N}{\Sigma}$ & 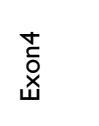 & 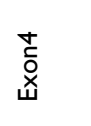 & 1 & $\frac{\infty}{\frac{\infty}{\tilde{x}}}$ \\
\hline 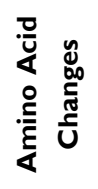 & 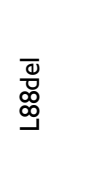 & $\begin{array}{l}\text { ơ⿱宀 } \\
\frac{0}{n}\end{array}$ & $\begin{array}{l}\underset{N}{\Sigma} \\
\stackrel{S}{S}\end{array}$ & 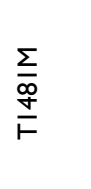 & $\begin{array}{l}\vec{J} \\
\underset{\sim}{\sim} \\
\stackrel{u}{n}\end{array}$ & 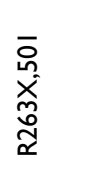 & 1 & 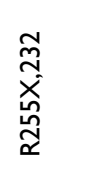 & 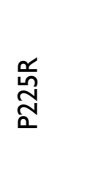 & 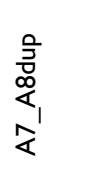 & 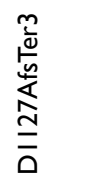 \\
\hline 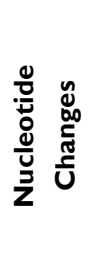 & 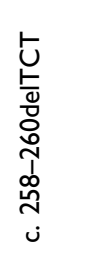 & 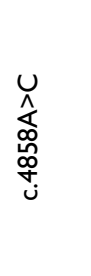 & & \begin{tabular}{l}
$\stackrel{r}{\hat{U}}$ \\
\multirow{̛}{J}{} \\
$\dot{J}$
\end{tabular} & 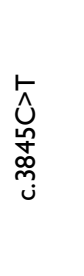 & $\begin{array}{l}\stackrel{\leftarrow}{\hat{U}} \\
\hat{\infty} \\
\stackrel{\infty}{ن}\end{array}$ & 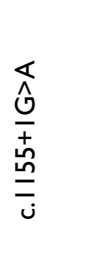 & 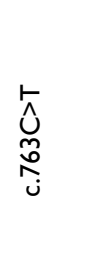 & 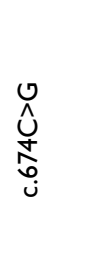 & 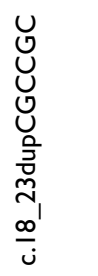 & 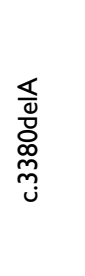 \\
\hline 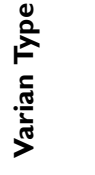 & 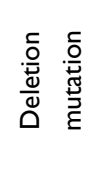 & 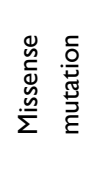 & 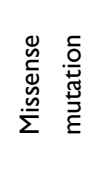 & 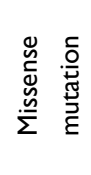 & 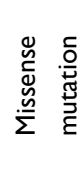 & 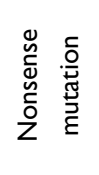 & 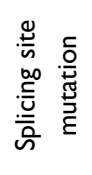 & 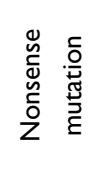 & 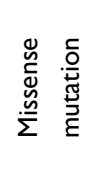 & 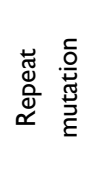 & 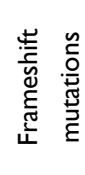 \\
\hline 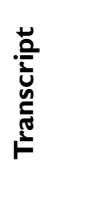 & 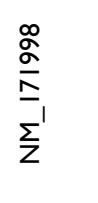 & 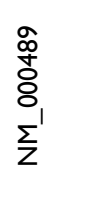 & $\begin{array}{l}\stackrel{0}{0} \\
\frac{\infty}{8} \\
\frac{\Sigma_{1}}{z}\end{array}$ & 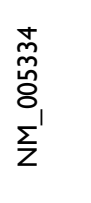 & 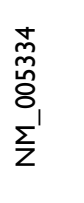 & $\begin{array}{l}\stackrel{\circ}{\rho} \\
\frac{m}{8} \\
\sum_{z}\end{array}$ & 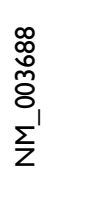 & $\begin{array}{l}\tilde{\alpha} \\
\sigma \alpha \\
\delta \\
\delta \\
\Sigma\end{array}$ & 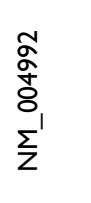 & 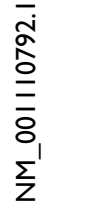 & 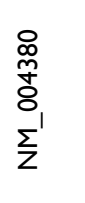 \\
\hline 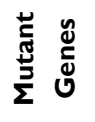 & 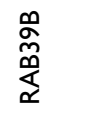 & $\begin{array}{l}\underset{\mathscr{\alpha}}{<} \\
\text { 孚 }\end{array}$ & $\underset{U}{Z}$ & 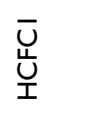 & $\begin{array}{l}\bar{U} \\
\bar{U} \\
\bar{I}\end{array}$ & 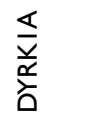 & 产 & $\underset{\tilde{U}}{\tilde{U}}$ & $\begin{array}{c}\tilde{U} \\
\stackrel{\mathrm{U}}{\Sigma}\end{array}$ & 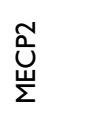 & 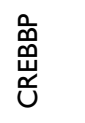 \\
\hline 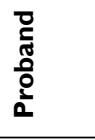 & - & $N$ & $m$ & 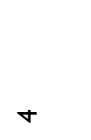 & in & 0 & $\wedge$ & $\infty$ & $\sigma$ & 으 & $=$ \\
\hline
\end{tabular}


Table 3 Global Analysis of the Gesell Results

\begin{tabular}{|c|c|c|c|c|c|}
\hline & Group & $\mathbf{N}$ & Average & SD & SE \\
\hline \multirow[t]{2}{*}{ Gross motor } & Gene-Positive & 10 & 51.5200 & 13.96319 & 4.41555 \\
\hline & Gene-negative & 7 & $40.7 \mid 43$ & 14.47658 & 5.47163 \\
\hline \multirow[t]{2}{*}{ Fine motor } & Gene-Positive & 10 & 47.7600 & 14.25476 & 4.50775 \\
\hline & Gene-negative & 7 & $37.7 \mid 43$ & 17.85790 & 6.74965 \\
\hline \multirow[t]{2}{*}{ Adaptability } & Gene-Positive & 10 & 48.1400 & II.84232 & 3.74487 \\
\hline & Gene-negative & 7 & 32.2857 & 20.58085 & 7.77883 \\
\hline \multirow[t]{2}{*}{ Language } & Gene-Positive & 10 & 44.4000 & 17.60808 & 5.56816 \\
\hline & Gene-negative & 7 & 37.2857 & 18.24568 & 6.89622 \\
\hline \multirow[t]{2}{*}{ Social Competence } & Gene-Positive & 10 & 47.1700 & $13.344 \mid 7$ & 4.21980 \\
\hline & Gene-negative & 7 & 42.0000 & $|8.2300|$ & 6.89030 \\
\hline
\end{tabular}

Table 4 Comparison of Gesell Results Between Gene Positive and Negative Group

\begin{tabular}{|c|c|c|c|c|c|}
\hline & & \multicolumn{2}{|c|}{ Levene Test } & & \\
\hline & & \multirow[t]{2}{*}{$\mathbf{F}$} & \multirow[t]{2}{*}{$\mathbf{P}$} & \multicolumn{2}{|c|}{$95 \% \mathrm{Cl}$} \\
\hline & & & & Lower Limit & Higher Limit \\
\hline Gross motor & $\begin{array}{l}\text { Using Equivalent variance } \\
\text { Not using Equivalent variance }\end{array}$ & 0.211 & 0.653 & $\begin{array}{l}-4.079 \mid 3 \\
-4.4 \mid 387\end{array}$ & $\begin{array}{l}25.69056 \\
26.02530\end{array}$ \\
\hline Fine motor & $\begin{array}{l}\text { Using Equivalent variance } \\
\text { Not using Equivalent variance }\end{array}$ & 0.410 & 0.532 & $\begin{array}{l}-6.54515 \\
-7.80348\end{array}$ & $\begin{array}{l}26.63658 \\
27.89491\end{array}$ \\
\hline Adaptability & $\begin{array}{l}\text { Using Equivalent variance } \\
\text { Not using Equivalent variance }\end{array}$ & 2.302 & 0.150 & $\begin{array}{l}-.87209 \\
-3.74745\end{array}$ & $\begin{array}{l}32.58066 \\
35.45602\end{array}$ \\
\hline Language & $\begin{array}{l}\text { Using Equivalent variance } \\
\text { Not using Equivalent variance }\end{array}$ & 0.024 & 0.879 & $\begin{array}{l}-11.65182 \\
-12.07116\end{array}$ & $\begin{array}{l}25.88039 \\
26.29973\end{array}$ \\
\hline Social Competence & $\begin{array}{l}\text { Using Equivalent variance } \\
\text { Not using Equivalent variance }\end{array}$ & 3.243 & 0.092 & $\begin{array}{l}-11.09489 \\
-|2.7457|\end{array}$ & $\begin{array}{l}21.43489 \\
23.08571\end{array}$ \\
\hline
\end{tabular}

\section{Acknowledgments}

We would like to acknowledge the hard and dedicated work of all the staff that implemented the intervention and evaluation components of the study.

\section{Funding}

Key Projects of National Key Research and Development Program (Project No. 2016YFC1306200).

\section{Disclosure}

All of the authors had no personal, financial, commercial, or academic conflicts of interest in this work.

\section{References}

1. Forseth B, Papanek PE, Polfuss ML. Feasibility and applicability of Evenson sedentary behavior cut points applied to children with and without intellectual and developmental disabilities. Disabil Rehabil. 2020;1-6. doi:10.1080/09638288.2020.1817160

2. Beheshtian M, Akhtarkhavari T, Mehvari S, et al. Comprehensive genotype-phenotype correlation in AP-4 deficiency syndrome; adding data from a large cohort of Iranian patients. Clin Genet. 2020. doi: $10.1111 /$ cge. 13845

3. Cervi F, Saletti V, Turner K, et al. The TAND checklist: a useful screening tool in children with tuberous sclerosis and neurofibromatosis type 1. Orphanet J Rare Dis. 2020;15(1):237. doi:10.1186/ s13023-020-01488-4

4. Lindgren S, Lauer E, Momany E, et al. Disability, hospital care, and cost: utilization of emergency and inpatient care by a cohort of children with intellectual and developmental disabilities. J Pediatr. 2020: S0022-3476(20)31120-3. doi:10.1016/j.jpeds.2020.08.084 
5. Umair M, Ballow M, Asiri A, et al. EMC10 homozygous variant identified in a family with global developmental delay, mild intellectual disability, and speech delay. Clin Genet. 2020;98(6):555-561. doi:10.1111/cge. 13842

6. Chen X, Kong L, Piltonen TT, Gissler M, Lavebratt C. Association of polycystic ovary syndrome or anovulatory infertility with offspring psychiatric and mild neurodevelopmental disorders: a Finnish population-based cohort study. Hum Reprod. 2020:deaa192.

7. Liang B, Wang Y, Lin N, et al. Single nucleotide polymorphism array analysis of 102 patients with developmental delay and/or intellectual disability from Fujian, China. Clin Chim Acta. 2020;510:638-643. doi:10.1016/j.cca.2020.08.032

8. Xu C, Yao M, Kang M, Duan G. Improving physical fitness of children with intellectual and developmental disabilities through an adapted rhythmic gymnastics program in China. Biomed Res Int. 2020;2020:2345607.

9. 1-Deri N, Okur V, Ahimaz P, et al. A novel homozygous variant in TRAPPC2L results in a neurodevelopmental disorder and disrupts TRAPP complex function. J Med Genet. 2020:jmedgenet-2020107016.

10. Negri G, Magini P, Milani D, et al. Exploring by whole exome sequencing patients with initial diagnosis of Rubinstein-Taybi syndrome: the interconnections of epigenetic machinery disorders. Hum Genet. 2019;138(3):257-269. doi:10.1007/s00439-019-01985-y

11. Spena S, Milani D, Rusconi D, et al. Insights into genotype-phenotype correlations from CREBBP point mutation screening in a cohort of 46 Rubinstein-Taybi syndrome patients. Clin Genet. 2014;12:1-10.

12. Roelfsema JH, Peters DJ. Rubinstein-Taybi syndrome: clinical and molecular overview. Expert Rev Mol Med. 2007;9(23):1-16. doi:10.1017/S1462399407000415
13. Chen D, Liu J, Wu Z, Li SH. Role of miR-132/methyl-CpG-binding protein 2 in the regulation of neural stem cell differentiation. Neural Regen Res. 2021;16(2):345-349. doi:10.4103/1673-5374.290908

14. Zhang X, Herr F, Vernochet A, Lorenzo HK, Beaudreuil S, Dürrbach A. CASK, the soluble glomerular permeability factor, is secreted by macrophages in patients with recurrent focal and segmental glomerulo-sclerosis. Front Immunol. 2020;11:875. doi:10.3389/fimmu.2020.00875

15. Ntonova A, Hummel B, Khavaran A, et al. Heat-shock protein 90 controls the expression of cell-cycle genes by stabilizing metazoan-specific host-cell factor HCFC1. Cell Rep. 2019;29 (6):1645-1659.e9. doi:10.1016/j.celrep.2019.09.084

16. Selenica P, Conlon N, Gonzalez C, et al. Genomic profiling aids classification of diagnostically challenging uterine mesenchymal tumors with myomelanocytic differentiation. Am J Surg Pathol. 2020. doi:10.1097/PAS.0000000000001572

17. Santoro C, Giugliano T, Bernardo P, et al. A novel RAB39B mutation and concurrent de novo NF1 mutation in a boy with neurofibromatosis type 1 , intellectual disability, and autism: a case report. $B M C$ Neurol. 2020;20(1):327. doi:10.1186/s12883-020-01911-0

18. Zhou P, He N, Zhang JW, et al. Novel mutations and phenotypes of epilepsy-associated genes in epileptic encephalopathies. Genes Brain Behav. 2018;17(8):e12456. doi:10.1111/gbb.12456

19. Lee HJ, Woo H, Lee HE, et al. The novel DYRK1A inhibitor KVN93 regulates cognitive function, amyloid-beta pathology, and neuroinflammation. Free Radic Biol Med. 2020:S0891-5849(20)31237-5.
International Journal of General Medicine

\section{Publish your work in this journal}

The International Journal of General Medicine is an international, peer-reviewed open-access journal that focuses on general and internal medicine, pathogenesis, epidemiology, diagnosis, monitoring and treatment protocols. The journal is characterized by the rapid reporting of reviews, original research and clinical studies

\section{Dovepress}

across all disease areas. The manuscript management system is completely online and includes a very quick and fair peer-review system, which is all easy to use. Visit http://www.dovepress.com/ testimonials.php to read real quotes from published authors. 